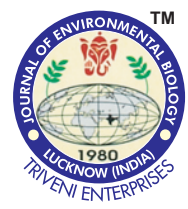

\title{
Photocatalytic degradation of methylene blue dye using dysprosium oxide/bismuth oxide nanocomposite
}

\begin{abstract}
Authors Info
K.S. Kumar*, V. Samynaathan, S. Kumar and B. Neeraja

Department of Chemical Engineering, Sri Sivasubramaniya Nadar College of Engineering, Kalavakkam - 603 110, India

*Corresponding Author Email : sathishkumark@ssn.edu.in

\section{Edited by}

Professor G. Manjula

\section{Reviewed by}

Dr. A. Gnanaprakasam

Dr. J. Iyyappan

\section{Abstract}

Aim: In the present study, we reported a facile synthesis of new $\mathrm{Dy}_{2} \mathrm{O}_{3} / \mathrm{Bi}_{2} \mathrm{O}_{3}$ nanocomposite and examined its photocatalytic activity by studying degradation of methylene blue dye under UV irradiation.

Methodology: Nano-catalyst was synthesised in situ wet chemical method and it was characterised by Scanning Electron Microscopy (SEM), Fluorescence spectroscopy, Energy-dispersive spectroscopy (EDS) and UV spectroscopy. Effects of degradation reaction parameters like initial dye concentration, photocatalyst load and $\mathrm{pH}$ of the effluent solution on the rate of degradation were studied.

Results: It was found that maximum percentage degradation was achieved at $60 \mathrm{ppm}$ initial dye concentration with a catalyst load of $0.5 \mathrm{~g} \mathrm{l}^{-1}$ and at neutral $\mathrm{pH}$ conditions. For degradation of $100 \mathrm{ppm}$ of methylene blue solution, catalyst load of $0.5 \mathrm{gl}^{-1}$ proved to be optimum at $\mathrm{pH}$ 7. Studies on the effect of $\mathrm{pH}$ indicates that the percentage degradation of dye increased as the $\mathrm{pH}$ of the solution increased.

Interpretation: It was found that the removal of dye with the prepared catalyst was highest at alkaline $\mathrm{pH}$. The optical studies showed that $\mathrm{Dy}_{2} \mathrm{O}_{3} / \mathrm{Bi}_{2} \mathrm{O}_{3}$ nanocomposite could be an effective photocatalyst than $\mathrm{Bi}_{2} \mathrm{O}_{3}$.

Key words : Dye degradation, Dysprosium oxide,Methylene blue, Nanocomposites, Photocatalysis
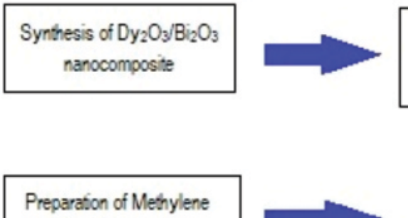
blue dye water
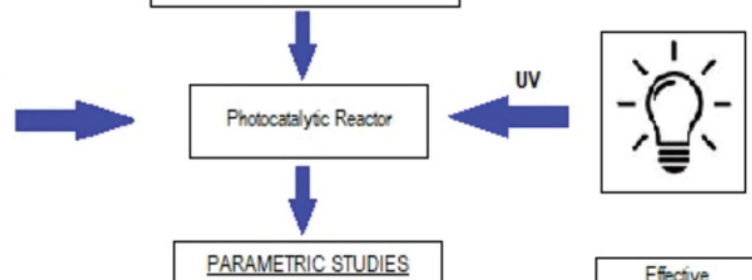

Effect of intial dye concentration, Effect of catalyst loading, Effect of $\mathrm{pH}$

How to cite : Kumar, K.S., V. Samynaathan, S. Kumar and B. Neeraja: Photocatalytic degradation of methylene blue dye using dysprosium oxide/bismuth oxide nanocomposite. J. Environ. Biol., 40, 825-831 (2019). DOI : http://doi.org/10.22438/jeb/40/4(SI)/JEB_30
\end{abstract}




\section{Introduction}

Synthetic dyes are found in the effluents discharged from a wide range of industries such as textile and tanneries. Effluent of these industries are heavily contaminated with dyes and pose harmful effects on the living organisms. About $20 \%$ of all dyes produced enter water bodies and cause environmental pollution. Methylene blue is commonly used in textile industries to dye fabrics and cotton wools. It can also be used a temporary hair colorant. Inhaling or consumption of this dye at high concentrations can lead to headache, high blood pressure, nausea, vomiting or diarrhoea. Sometimes it can even induce allergic reactions (Patil, 2011). It, thus, becomes essential to harm the concentration of this dye effluent to prevent excessive damage to human beings, as well as the environment. Conventional techniques such as adsorption, ultrafiltration and chemical coagulation transfer dye from liquid phase to solid phase causing secondary pollution. Other techniques such as chlorination and ozonation are found to proceed at a slower rate and the operational cost is high (Narayan et al., 2016). Therefore, Advanced Oxidation Processes (AOPs) are employed for degradation of dyes and many other organic molecules in wastewater treatment. These processes generally involve oxidative degradation of contaminants.

Semiconductor photocatalysis is one of the newly developed AOP, which can be employed for the degradation of dye. In light-induced-redox-reactions, semiconductors such as $\mathrm{TiO}_{2}$ act as sensitizers due to their electronic structure. They are characterised by a filled valence bond and empty conduction band. When they are exposed to electromagnetic radiation, electrons from the valence band are promoted to conduction band leaving a hole behind. These electron-hole pairs recombine with other molecules producing powerful oxidising species such as hydroxyl or super-oxide radicals (Chakrabarti and Dutta, 2004).

Bismuth oxide $\left(\mathrm{Bi}_{2} \mathrm{O}_{3}\right)$ is used in various areas like sensor technology, gas sensors, capacitors and optical coatings due to high refractive index, dielectric permittivity, considerable photoconductivity and photoluminescent properties(Liu et al., 2013). $\mathrm{Bi}_{2} \mathrm{O}_{3}$ has five main polymorphic forms, viz. $\alpha-, \beta-, \gamma-, \delta$ - and $\omega-\mathrm{Bi}_{2} \mathrm{O}_{3}$ (Monnereau et al., 2003). Among them, the lowtemperature a-phase has a bandgap of $2.85 \mathrm{eV}$ while high temperature $\beta$-phase has a bandgap energy of $2.58 \mathrm{eV}$ (Dolocan, 1978). Hence, bismuth oxide shows excellent photocatalytic activity. However, the quick recombination of charge carriers that are photogenerated has reduced the photocatalytic performance of $\mathrm{Bi}_{2} \mathrm{O}_{3}$ significantly (Liu et al., 2011). $\mathrm{Bi}_{2} \mathrm{O}_{3}$ nanoparticles have also been able to show their efficacy as photocatalyst for degradation of Orange II from wastewater under visible light irradiation (Bessekhouad et al., 2005). Additionally, the synthesis procedure of $\mathrm{Bi}_{2} \mathrm{O}_{3}$ strongly influences catalytic activity (Pugazhenthiran et al., 2011). Hence, the presence of $\mathrm{Bi}_{2} \mathrm{O}_{3}$ in a suitable nanocomposite may strongly favour photocatalysis.

Coupled semiconductor photocatalysts may increase the photocatalytic efficiency. This might be due to the increase in the charge separation and extending the visible light absorption. The rare-earth metals and their oxides may be doped in $\mathrm{Bi}_{2} \mathrm{O}_{3}$ to increase conversion efficiency as a result of their unique $f$ and $d$ electron orbital structure (Li and Yan, 2009).With the highest magnetic moment and susceptibility, dysprosium a lanthanide metal and its oxide have gained interest to researchers. The use of dysprosium oxide as a photocatalyst is increasing due to its paramagnetic nature along with its high degrading activity and large surface area. Combining the properties of both bismuth oxide and dysprosium oxide in a nanocomposite is expected to have a low band gap energy and the photocatalytic activity can be improved (Tamm et al., 2015).

In the present study, $\mathrm{Dy}_{2} \mathrm{O}_{3} / \mathrm{Bi}_{2} \mathrm{O}_{3}$ nanocomposite was synthesized by in situ wet chemical method and their photo catalytic performance in methylene blue dye under UV light irradiation. The obtained nano-catalyst was characterised by Scanning Electron Microscope, Fluorescence spectroscopy, Energy-dispersive spectroscopy and UV spectroscopy. Effects of initial dye concentration, photocatalyst loading and $\mathrm{pH}$ on the rate of degradation were also studied.

\section{Materials and Methods}

Preparation of $\mathrm{Dy}_{2} \mathrm{O}_{3} / \mathrm{Bi}_{2} \mathrm{O}_{3}$ nanocomposite: $\mathrm{Dy}_{2} \mathrm{O}_{3} / \mathrm{Bi}_{2} \mathrm{O}_{3}$ nanocomposite was synthesised by following the procedure of $\mathrm{Li}$ and Yan (2009) with slight modifications. One gram of dysprosium nitrate pentahydrate was mixed with $2.5 \mathrm{~g}$ of bismuth nitrate pentahydrate in a beaker. The above mixture was stirred along with sodium hydroxide solvent for about $30 \mathrm{~min}$. The resultant precipitate was filtered and then dried in a hot air oven at $100^{\circ} \mathrm{C}$ for $12 \mathrm{hrs}$. At last, the precursors were heat treated in a furnace at $500^{\circ} \mathrm{C}$ for about 5 hrs to obtain $\mathrm{Dy}_{2} \mathrm{O}_{3} / \mathrm{Bi}_{2} \mathrm{O}_{3}$ nanocomposite. The resultant composite was used as a catalyst without further processing. The composite obtained were then characterised by Scanning Electron Microscopy.

The Scanning Electron Microscopy was done with COXEM CX 200 TM scanning electron microscope at Microlabs, Chennai. The amount of degradation of dye was measured by measuring the absorbance values of different samples using UV Visible Spectroscopy. The characterisation was done with Jasco V-630 UV-Visible spectrophotometer and diffuse reflectance spectra of the samples were recorded in the wavelength range 200-800nm using a Jasco V-650 spectrophotometer. Photoluminescence spectra were recorded with a Jasco spectrofluorophotometer Model FP- 8300.

Photodegradation of methylene blue dye: The experiment was conducted using a laboratory photoreactor system made up of borosilicate glass. A double walled immersion well, made of 
quartz was placed inside the glass reactor fitted with a standard joint. The capacity of photo reactor was $850 \mathrm{ml}$, however the total volume of the solution taken was $750 \mathrm{ml}$. A 8W pressure mercury vapour lamp was placed inside the immersion well. This entire setup was placed on a magnetic stirrer for uniform dissipation of heat produced during the reaction. Experiments were performed by varying the concentration of dye solution $(60 \mathrm{ppm}, 80 \mathrm{ppm}, 100$ ppm and $120 \mathrm{ppm})$, amount of catalyst (0.1-1 $\left.\mathrm{gl}^{-1}\right)$ and $\mathrm{pH}(4-12)$. $750 \mathrm{ml}$ of this dye solution was taken in a photoreactor and photocatalyst $\left(\mathrm{Dy}_{2} \mathrm{O}_{3} / \mathrm{Bi}_{2} \mathrm{O}_{3}\right)$ was added to dye solution, and the suspension was subjected to irradiation under UV lamp. The aqueous solution was magnetically stirred. Aliquot was taken out at different time intervals with the help of a glass syringe. $\mathrm{Dy}_{2} \mathrm{O}_{3} / \mathrm{Bi}_{2} \mathrm{O}_{3}$ catalyst particles were centrifuged after photocatalysis. This degraded solution was taken for measuring spectra.

Reagents: Pure grades of dysprosium nitrate pentahydrate $\left(\mathrm{Dy}\left(\mathrm{NO}_{3}\right)_{3} \cdot 5 \mathrm{H}_{2} \mathrm{O}\right)$, bismuth nitrate pentahydrate $\left(\mathrm{Bi}\left(\mathrm{NO}_{3}\right)_{3} \cdot 5 \mathrm{H}_{2} \mathrm{O}\right)$, sodium hydroxide and methylene blue $\left(\mathrm{C}_{16} \mathrm{H}_{18} \mathrm{CIN}_{3} \mathrm{~S}\right)$ dye were purchased from Sigma Aldrich and were used without further treatment. Methylene blue dye was used to prepare simulated waste water to carry out experimental work. The solutions were prepared using deionised water unless otherwise specified. All the chemicals used were of analytical grade.

\section{Results and Discussion}

Scanning electron microscopy was performed to study the surface morphology and particle size of nanocomposite. SEM images showed that the surface of composite was quite smooth and the size of composite particles were in nano scale. An increased magnification showed spherical shape of nanoparticles with 30-40 nm diameter. The images indicate that the particles were non-porous and formed irregular shaped clusters. Fig. 2 shows the energy-dispersive spectroscopy of $\mathrm{Dy}_{2} \mathrm{O}_{3} / \mathrm{Bi}_{2} \mathrm{O}_{3}$ nanocomposite. The peaks of bismuth and dysprosium in the EDS profile showed existence of bismuth oxide and dysprosium oxide in the nanocomposite. EDS showed the 33 $\%$ bismuth and $55 \%$ dysprosium in nano composite.

The optical properties of prepared $\mathrm{Dy}_{2} \mathrm{O}_{3} / \mathrm{Bi}_{2} \mathrm{O}_{3}$ samples were explored by UV-Vis diffuse reflectance spectroscopy and photoluminescence spectroscopy. UV-Vis diffuse reflectance absorption spectra are shown in Fig. 3. The absorbance was maximum in the UV region. Fig. 4 shows the photoluminescence spectra of prepared $\mathrm{Dy}_{2} \mathrm{O}_{3} / \mathrm{Bi}_{2} \mathrm{O}_{3}$ nanocomposite. The observed peak positions and shapes of the photoluminescence spectra were almost identical for both $\mathrm{Bi}_{2} \mathrm{O}_{3}$ and $\mathrm{Dy}_{2} \mathrm{O}_{3} / \mathrm{Bi}_{2} \mathrm{O}_{3}$ nanocomposite which might be due to radiative recombination process and self-trapped excitations (Pugazhenthiran et al., 2011). The photoluminescence spectra of nanocomposite gave two band emission peaks at 420 and $470 \mathrm{~nm}$. The low emission peak at $420 \mathrm{~nm}$ is attributed due to vacancies and surface defects present in the nanocomposite (Kalpana and Selvaraj, 2016). The presence of these defects reduce the recombination of lightgenerated electron-hole pairs. Hence, the presence of $\mathrm{Dy}_{2} \mathrm{O}_{3}$ in a suitable nanocomposite with $\mathrm{Bi}_{2} \mathrm{O}_{3}$ may strongly favour photocatalysis.

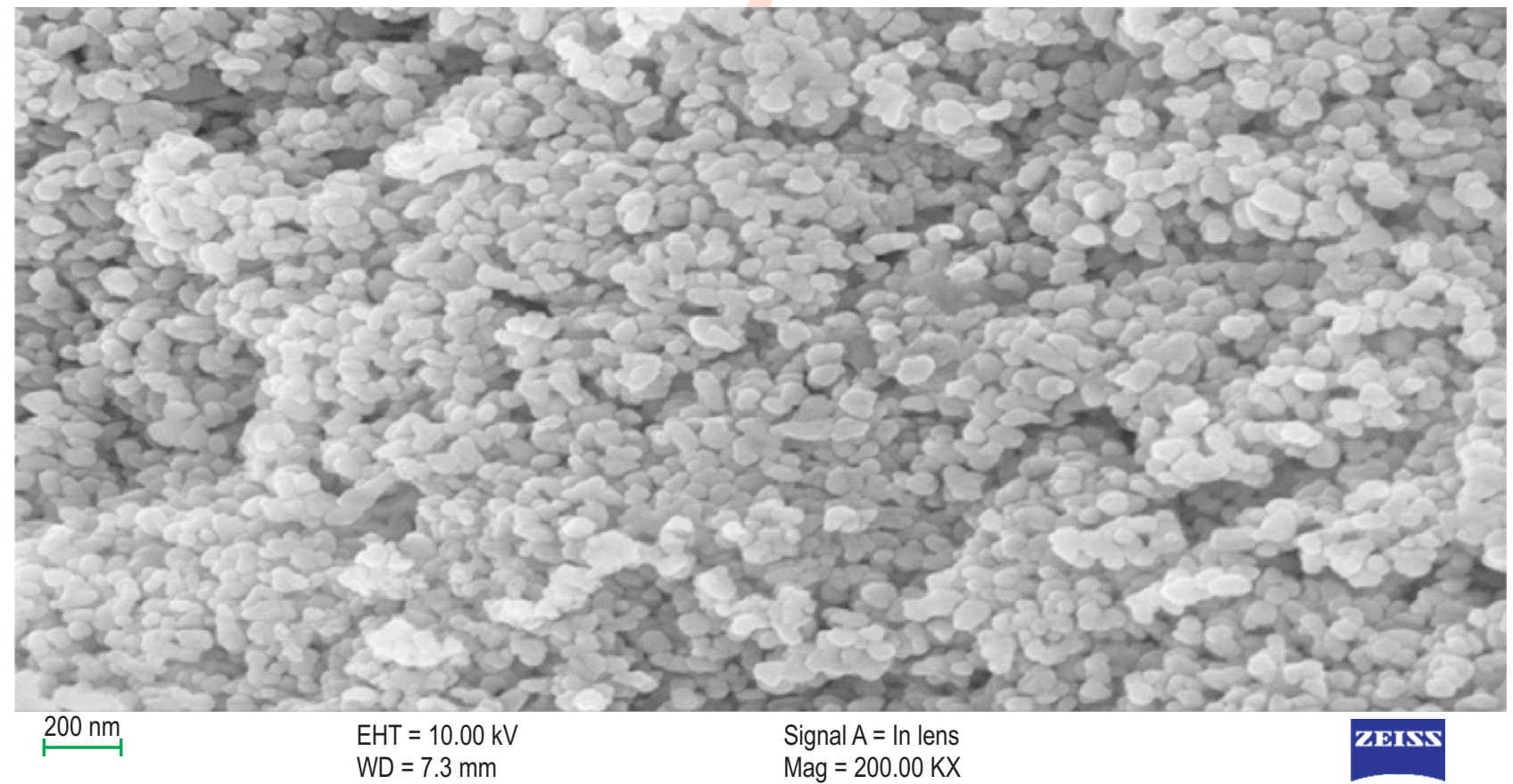

Fig. 1 : SEM analysis of nanocomposite. 


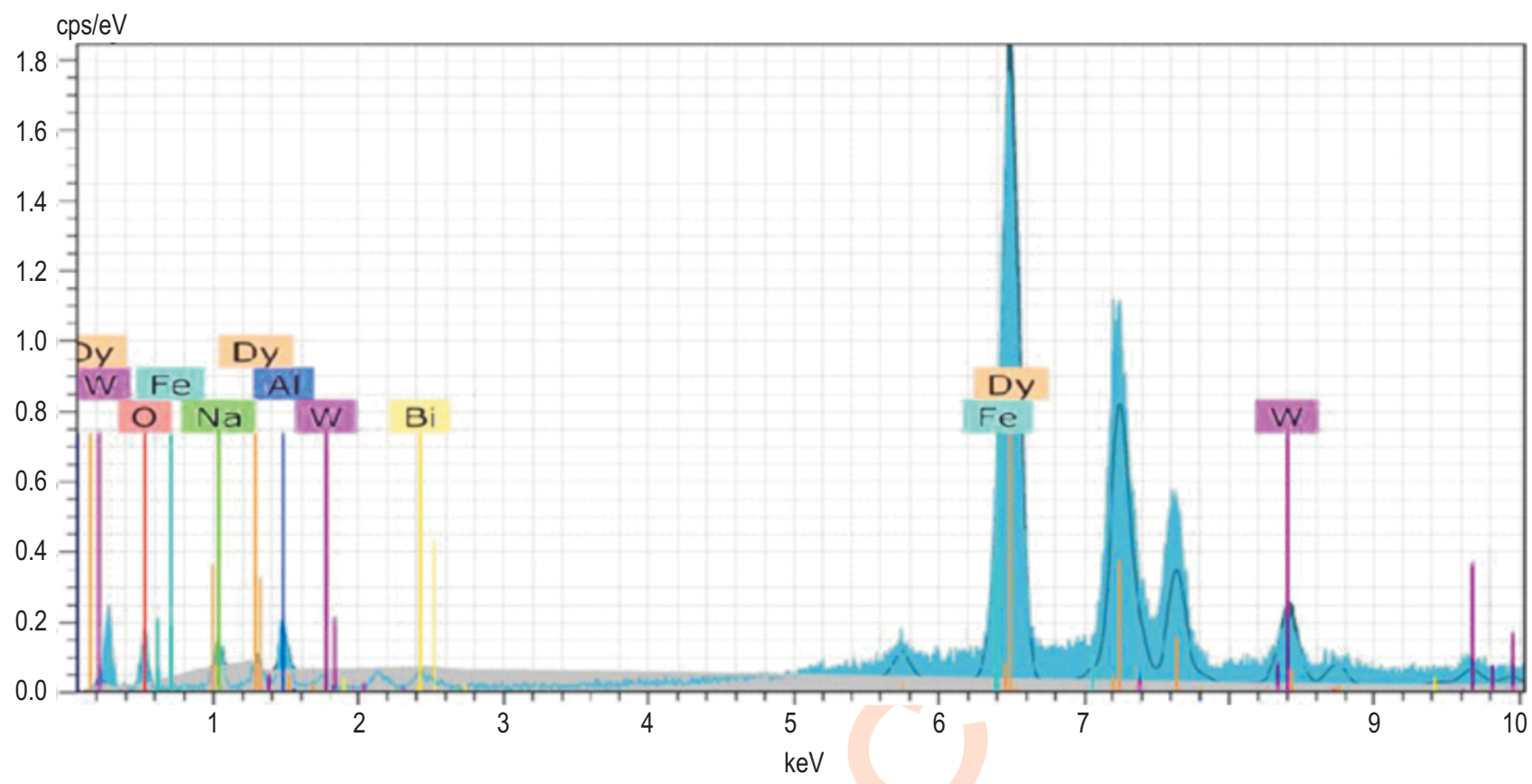

Fig. 2 : EDS analysis of nanocomposite.

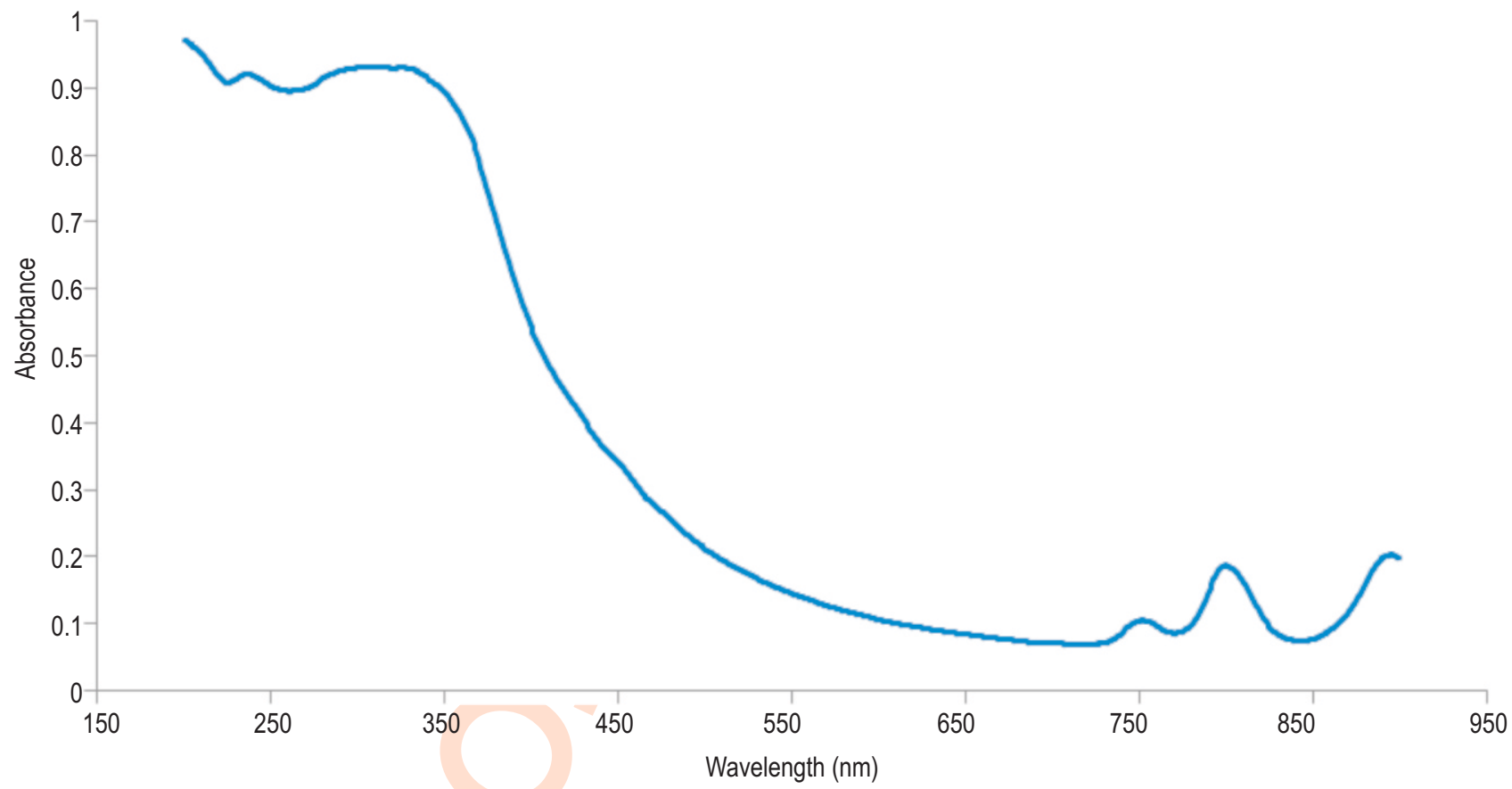

Fig. 3 : UV DRS of nanocomposite.

Experiments were carried out by varying the dye concentration from $60 \mathrm{ppm}$ to $100 \mathrm{ppm}$ at neutral $\mathrm{pH}$ for a catalyst loading of $0.5 \mathrm{gl}^{-1}$. The percentage dye degraded was recorded at an interval of $10 \mathrm{~min}$. From Fig. 5, it is evident that the rate of degradation decreased with increase in dye concentration. The time taken for $95 \%$ degradation of dye for 60 and $80 \mathrm{ppm}$ dye concentration was around 70 min whereas it took 120 min for degrading $100 \mathrm{ppm}$ and $120 \mathrm{ppm}$ of dye. As the concentration of dye in the solution increased, the dye was deposited on the surface of the catalyst. Since penetration of light in the catalyst molecules decreased, there was a decrease in overall degradation of dye. Degradation rate depends on the probability of formation of $\mathrm{OH}^{-}$radicals which decreases as dye molecules occupy active sites of photocatalyst (Reza et al., 2017). Thus, the 


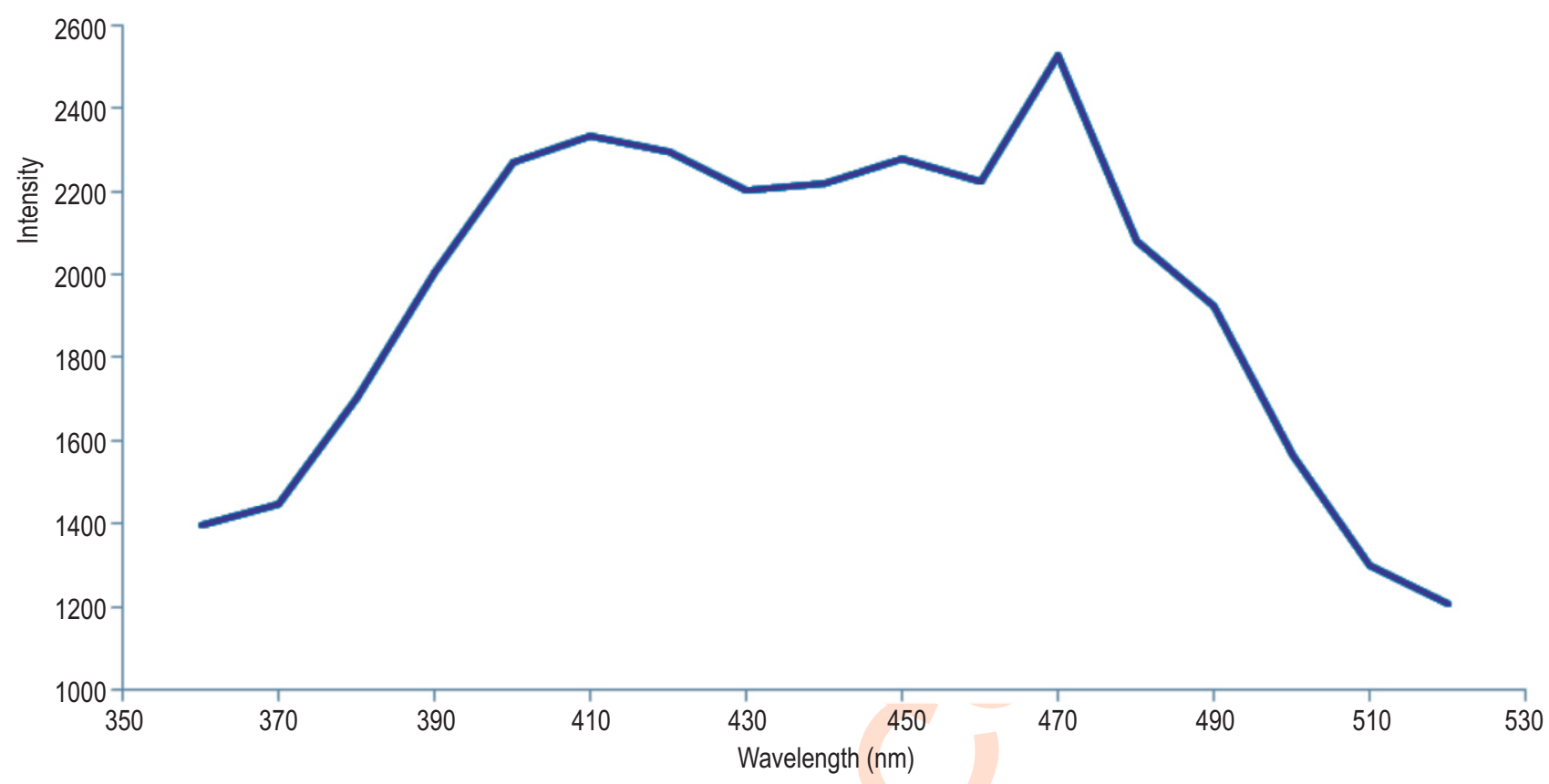

Fig. 4 : Photoluminescence spectra of nanocomposite (excited at $300 \mathrm{~nm}$ ).

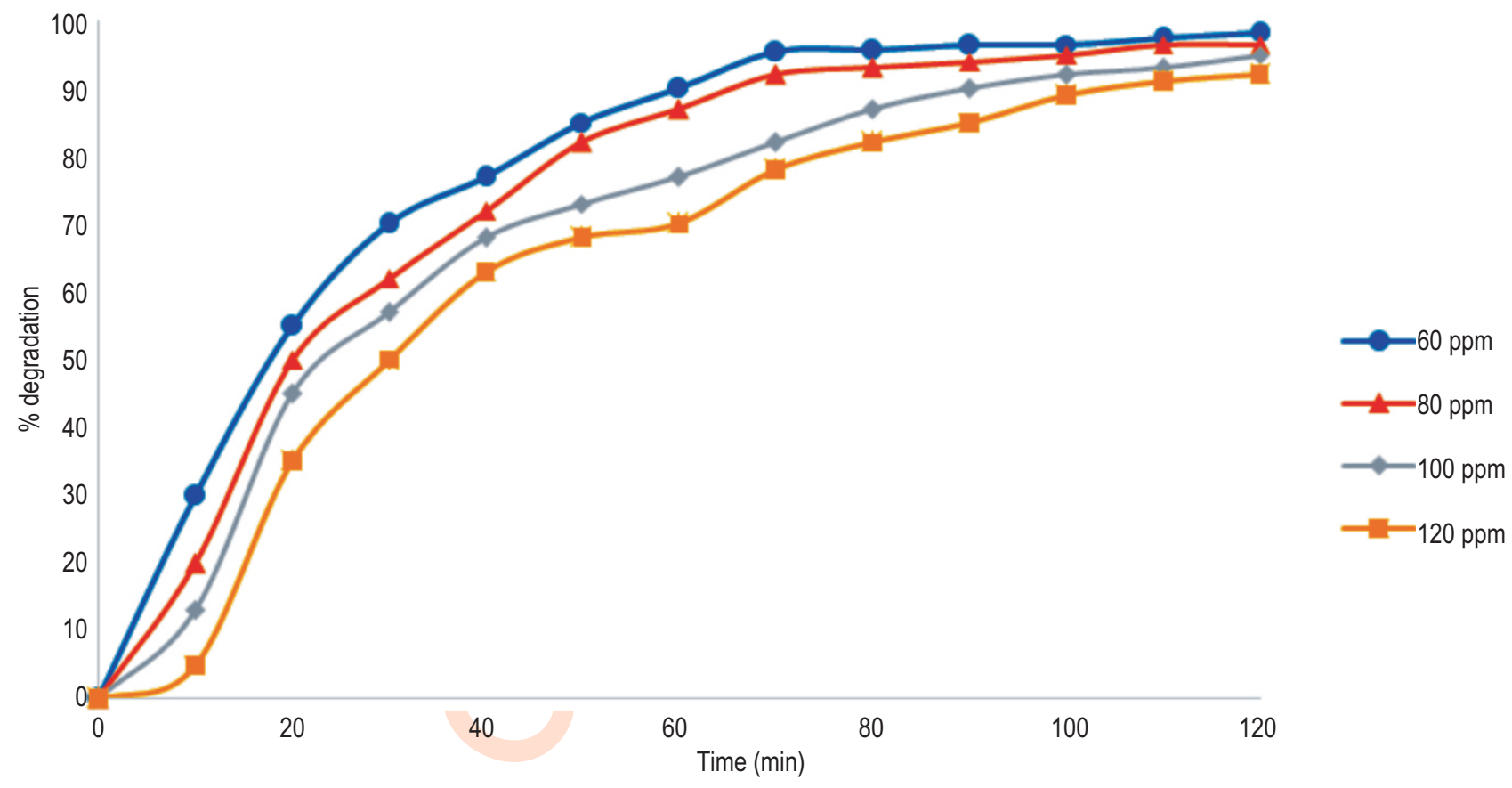

Fig. 5 : Effect of varying initial concentration of dye.

highest rate of degradation of methylene blue dye was observed $60 \mathrm{ppm}$ dye concentration while the optimum dye concentration for $0.5 \mathrm{gl}^{-1}$ of photocatalyst was $80 \mathrm{ppm}$.

The concentration of photocatalyst affects the overall rate of degradation. Therefore, it is mandatory to determine the minimum amount of photocatalyst required for maximum degradation. To determine this, experiments were carried out by fixing the dye concentration at $100 \mathrm{ppm}$ at neutral $\mathrm{pH}$ and the results are shown in Fig 6. The amount of catalyst varied from 0.1 to $1 \mathrm{gl}^{-1}$ and the percent dye degraded after 120 min was recorded. At a catalyst concentration of $0.1 \mathrm{gl}^{-1}$, the percentage degradation 


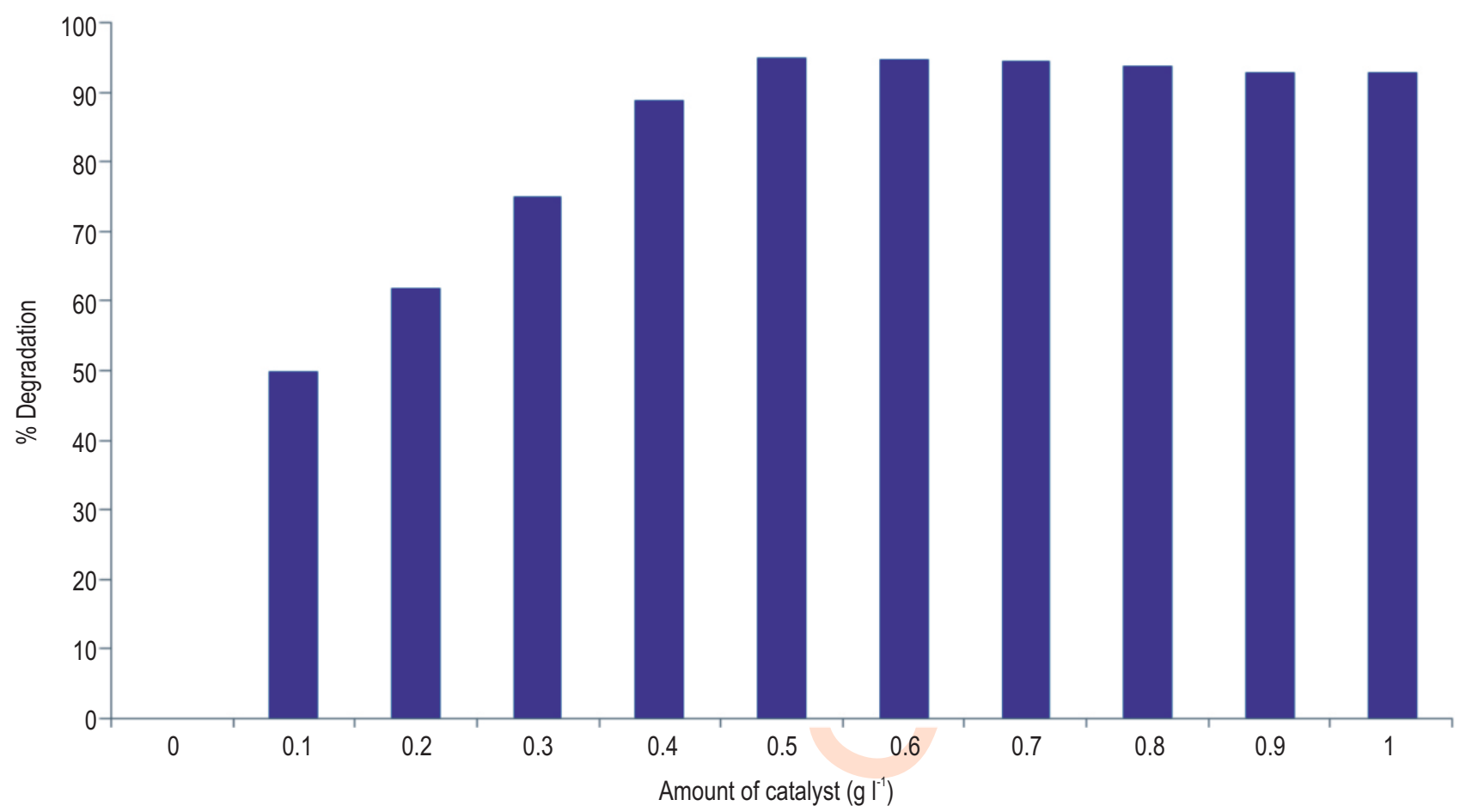

Fig. 6 : Effect of catalyst loading on degradation of methylene blue.

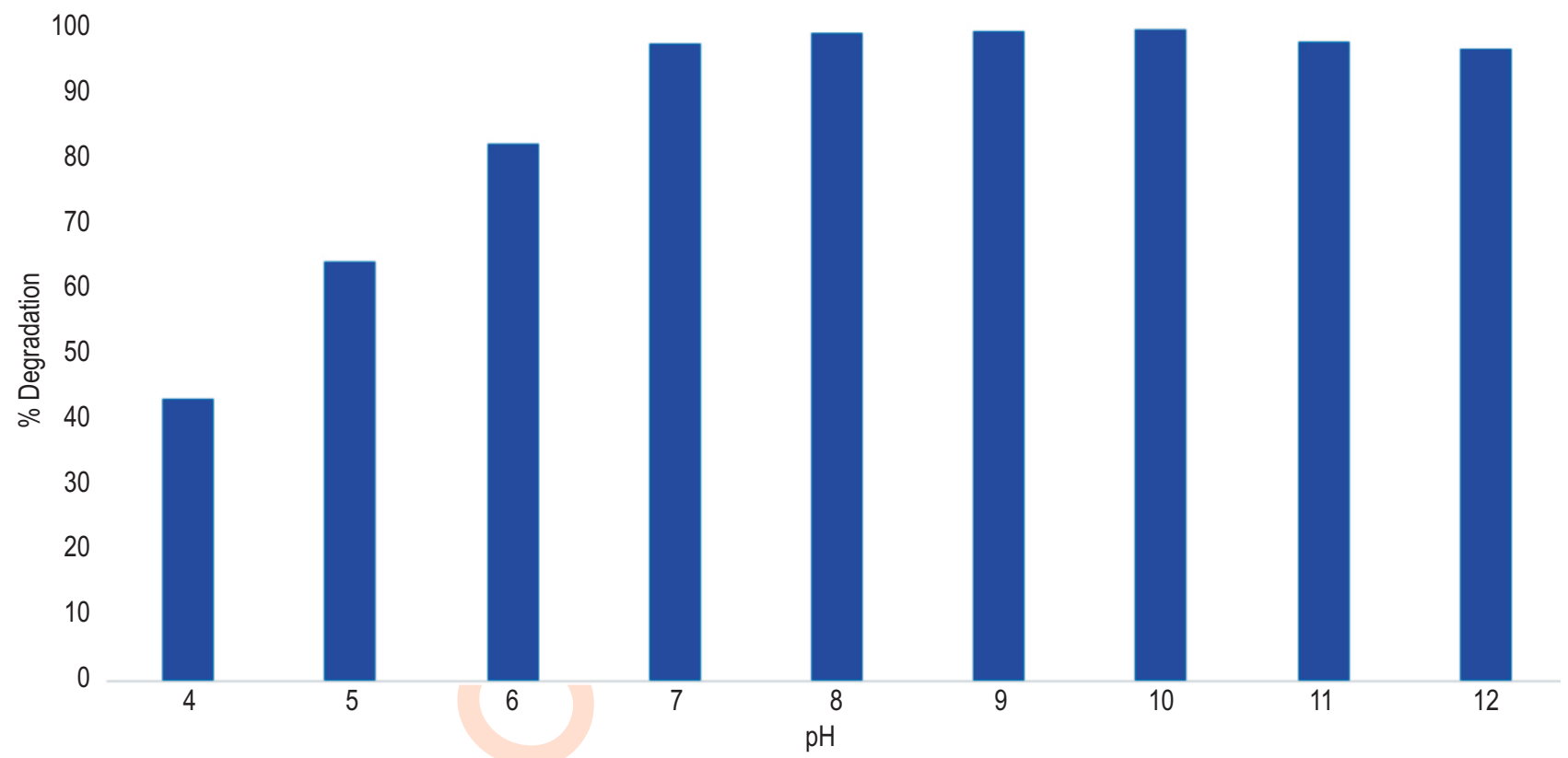

Fig. 7 : Effect of pH on degradation of methylene blue.

of methylene blue dye after $2 \mathrm{hr}$ was $50 \%$. The percent dye degradation increased with increase in catalyst concentration upto $0.5 \mathrm{~g} \mathrm{l}^{-1}$. As the catalyst loading increased, the quantity of photon adsorbed and the rate of degradation increased (Herrmann 1995; Sobana et al., 2006). However, increasing the catalyst concentration beyond $0.5 \mathrm{~g} \mathrm{l}^{-1}$, there was no significant increase in the percent dye degradation. On increasing the catalyst concentration further, the percent dye degraded decreased slightly. This could be attributed to the fact that excess $\mathrm{Dy}_{2} \mathrm{O}_{3} / \mathrm{Bi}_{2} \mathrm{O}_{3}$ catalyst creates a light screening effect that reduces the area exposed to UV light, thereby decreasing the photocatalytic efficiency (Chong et al., 2010). Thus, for degradation of $100 \mathrm{ppm}$ methylene blue dye solution, the optimum catalyst load was $0.5 \mathrm{gl}^{-1}$. 
In heterogeneous photocatalysis, $\mathrm{pH}$ is one of the most important operating parameters that affect the charge on the catalyst particles (Chong et al., 2010). The molecular structure and functional groups present in the dye also has a significant effect on the photocatalytic degradation. Therefore, it is mandatory to determine the optimum $\mathrm{pH}$ of solution required for maximum degradation. To determine this, experiments were carried out by fixing the dye concentration at $100 \mathrm{ppm}$ and catalyst load of $0.5 \mathrm{gl}^{-1}$. The $\mathrm{pH}$ varied from 4 to 12 and the percent dye degraded after 120 min was recorded. Fig. 7 shows the effect of $\mathrm{pH}$ on dye degradation. It is evident that the percent dye degradation increased as $\mathrm{pH}$ increased, with maximum degradation percent at $\mathrm{pH} 10$. There was no significant increase in the percent degradation above $\mathrm{pH} 10$. This behaviour is attributed to the cationic nature of methylene blue dye. Hence, an alkaline solution will help the catalyst to carry a negative charge which will help in the adsorption of methylene blue dye on photocatalyst. On the contrary, acidic solution will limit the adsorption(Tang et al., 2005; Bubacz et al., 2010).

From the results of parametric studies, it can be concluded that $\mathrm{Dy}_{2} \mathrm{O}_{3} / \mathrm{Bi}_{2} \mathrm{O}_{3}$ nanocomposite is found to be an efficient photocatalyst for degradation of methylene blue dye which was further confirmed by SEM analysis and photoluminescence studies.

\section{References}

Bessekhouad, Y., D. Robert and J.V. Weber: Photocatalytic activity of $\mathrm{Cu}_{2} \mathrm{O} / \mathrm{TiO}_{2}, \mathrm{Bi}_{2} \mathrm{O}_{3} / \mathrm{TiO}_{2}$ and $\mathrm{ZnMn}_{2} \mathrm{O}_{4} / \mathrm{TiO}_{2}$ heterojunctions. Catal Today, 101, 315-321 (2005).

Bubacz, K., J. Choina, D. Dolat and A.W. Morawski: Methylene blue and phenol photocatalytic degradation on nanoparticles of anatase $\mathrm{TiO}_{2}$. Polish. J. Environ. Stud., 19, 685-691(2010)

Chakrabarti, S. and B.K. Dutta: Photocatalytic degradation of model textile dyes in wastewater using $\mathrm{ZnO}$ as semiconductor catalyst. J. Hazard. Mater., 112, 269-278 (2004).

Chong, M.N., B. Jin, C.W.K. Chow and C. Saint: Recent developments in photocatalytic water treatment technology: A review. Wat. Res., 44, 2997-3027 (2010).

Dolocan, V.: Transmission spectra of bismuth trioxide thin films. Appl.
Phys., 16, 405-407 (1978).

Herrmann. J.M.: Heterogeneous photocatalysis: An emerging discipline involving multiphase systems. Catal. Today, 24, 157-164 (1995).

Kalpana, K. and V. Selvaraj: Development of ZnS/SnS/A-FA nanorods at ambient temperature: Binary catalyst for the removal of congo red dye and pathogenic bacteria from wastewater. J. Ind. Eng. Chem., 41, 105-113 (2016).

$\mathrm{Li}$, L. and B. Yan: $\mathrm{CeO}_{2}-\mathrm{Bi}_{2} \mathrm{O}_{3}$ nanocomposite: Two step synthesis, microstructure and photocatalytic activity. J. Non. Cryst. Solids, 355, 776-779 (2009).

Liu, X., H. Cao and J. Yin: Generation and photocatalytic activities of $\mathrm{Bi} @ \mathrm{Bi}_{2} \mathrm{O}_{3}$ microspheres. Nano Res., 4, 470-482 (2011).

Liu, X., L. Pan, T. Lv, Z. Sun and C.Q. Sun: Visible light photocatalytic degradation of dyes by bismuth: Oxide-reduced graphene oxide composites prepared via: Microwave-assisted method. J. Coll. Interf. Sci., 408, 145-150 (2013).

Monnereau, O., L. Tortet, P. Llewellyn, F. Rouquerol and G. Vacquier: Synthesis of $\mathrm{Bi}_{2} \mathrm{O}_{3}$ by controlled transformation rate thermal analysis: A new route for this oxide? Solid State lonics, 157, 163-169 (2003).

Narayan, R.B., R. Goutham, B. Srikanth and K.P. Gopinath: A novel nano-sized calcium hydroxidecatalyst prepared from clam shells for the photodegradation of methyl red dye. J. Environ. Chem. Eng., 6, 3640-3647 (2018).

Patil, V.B.: A comparative study on photo degradation of methylene blue dye effluent by advanced oxidation process by using $\mathrm{TiO}_{2} / \mathrm{ZnO}$ photo catalyst. Rasayan J., 4, 814-819(2011).

Pugazhenthiran, N., P. Sathishkumar, S. Murugesan and S. Anandan: Effective degradation of acid orange 10 by catalytic ozonation in the presence of $\mathrm{Au}-\mathrm{Bi}_{2} \mathrm{O}_{3}$ nanoparticles. Chem. Eng. J., 168, 1227-1233 (2011).

Reza, K.M., A. Kurny and F. Gulshan: Parameters affecting the photocatalytic degradation of dyes using TiO2: A review. Appl. Water Sci. , 7, 1569-1578 (2017).

Sobana, N., M. Muruganadham and M. Swaminathan: Nano-Ag particles doped $\mathrm{TiO}_{2}$ for efficient photodegradation of direct azo dyes. $\mathrm{J}$. Mol. Catal. A. Chem., 258, 124-132 (2006).

Tamm, A., J. Kozlova, L. Aarik, J. Aarik, K. Kukli, J. Link and R. Stern: Dysprosium oxide and dysprosium-oxide-doped titanium oxide thin films grown by atomic layer deposition. J. Vac. Sci. Technol. A, 33, 01A127 (2015).

Tang, J., Z. Zou and J. Ye: Kinetics of MB degradation and effect of $\mathrm{pH}$ on the photocatalytic activity of $\mathrm{MIn}_{2} \mathrm{O}_{4}(\mathrm{M}=\mathrm{Ca}, \mathrm{Sr}, \mathrm{Ba})$ under visible light irradiation. Res. Chem. Intermed., 31, 513-519 (2005). 